Upaya Peningkatan Mutu...(Mulyadi et al.)

\title{
UPAYA PENINGKATAN MUTU SEKOLAH DENGAN STRATEG BAURAN PEMASARAN UNTUK KEPUASAN PELANGGAN PADA SMP MUHAMMADIYAH SINAR FAJAR CAWAS DAN SMPIT MUHAMMADIYAH AN NAJAH JATINOM KLATEN
}

\author{
Agus Mulyadi, Eko Supriyanto, Muthoifin, Sudarno Shobron \\ Magister Penidikan Agama Islam Sekolah Pascasarjana \\ Universitas Muhammadiyah Surakarta \\ E-Mail: hafimulya@yahoo.co.id, es113@ums.ac.id², mut122@ums.ac.id*
}

\begin{abstract}
Education is an important thing in life, currently, the education sector is becoming a marginalized part. The right strategy is needed so that the world of education is more advanced and quality. Muhammadiyah Middle School Sinar Fajar Cawas and Muhammadiyah Integrated Islamic Middle School An Najah Jatinom is a new school whose existence has received a good response from the community. The school applies a marketing mix strategy to improve the quality of schools. This research was carried out aiming to find out the steps, supporting and inhibiting factors in the implementation of the Marketing Mix strategy in the Muhammadiyah Junior High School, Sinar Fajar Cawas and in the Integrated Islamic Middle School Muhammadiyah An Najah Jatinom Klaten. This research uses field research methods. Data obtained by observation, interview, and documentation. The steps thathavebeen taken in implementing the Marketing Mix strategy to improve the quality of schools in Muhammadiyah Junior High School Sinar Fajar Cawas and Muhammadiyah Integrated Islamic Middle School An Najah Jatinom Klaten is by applying the 7P step, the step includes, the Product (product) in the form of a variety of selected programs. Price (price), in the form of school fees offered to student guardians with a payment system, can be done directly or via transfer. Place, strategic locations of both schools can be reached by public and private transportation. Promotion is carried out through print, electronic and social media. People (human resources) include educators and education staff who are young and enthusiastic. Physical evidence in the form of school buildings and student learning outcomes reports. Process, the implementation of education in the two schools has met the national education standards. Supporting factors in the implementation of the Marketing Mix strategy at the Muhammadiyah Junior High School Sinar Fajar Cawas are high public interest, educators (teachers) who are still young, passionate and have high creativity, varied programs, educative figures that are represented by prospective students and parents of students. The inhibiting factors in the implementation of the Marketing Mix strategy in Muhammadiyah Sinar Fajar Junior High School are, the lack of school facilities and infrastructure, the network outside of school which is still minimal, and the limited human resources in terms of quantity and quality. Supporting factors in the implementation of the Marketing Mix strategy at An Najah Jatinom Integrated Islamic Middle School are high public interest, young educators (teachers), enthusiasm and high creativity, good, comfortable, and attractive school buildings, and varied programs. The inhibiting factors in the implementation of the Marketing Mix strategy at Muhammadiyah Integrated Islamic Middle School An Najah Jatinom are, the teaching staff is still minimal in terms of quantity and quality,
\end{abstract}


the school is less consistent in program implementation and the lack of learning support facilities.

Keywords: marketing mix strategy; school quality; customer satisfaction

Abstrak: Pendidikan merupakan hal penting dalam kehidupan, saat ini sektor pendidikan menjadi bagian yang termarjinalkan. Perlu adanya strategi yang tepat agar dunia pendidikan lebih maju dan bermutu. SMP Muhammadiyah Sinar Fajar Cawas dan SMP Islam Terpadu Muhammadiyah An Najah Jatinom merupakan sekolah baru yang keberadaannya mendapat respon bagus dari masyarakat.

Sekolah tersebut menerapkan strategi bauran pemasaran untuk meningkatkan mutu sekolah. Penelitan ini dilakukan bertujuan untuk mengetahui langkah-langkah, faktor pendukung dan penghambat dalam penerapan strategi Bauran Pemasaran di SMP Muhammadiyah Sinar Fajar Cawas dan di SMP Islam Terpadu Muhammadiyah An Najah Jatinom Klaten. Penelitian ini menggunakan metode penelitian lapangan. Data diperoleh dengan cara pengamatan, wawancara dan dokumentasi. Langkah - langkah yang telah dilakukan dalam penerapan strategi Bauran Pemasaran untuk meningkatkan mutu sekolah di SMP Muhammadiyah Sinar Fajar Cawas dan SMP Islam Terpadu Muhammadiyah An Najah Jatinom Klaten adalah dengan menerapkan langkah $7 P$, langkah tersebut meliputi, Product (produk) yang berupa variasi program pilihan. Price (harga), berupa biaya sekolah yang ditawarkan pada wali murid dengan sistem pembayaran dapat dilakukan secara langsung atau melalui transfer. Place (tempat), lokasi kedua sekolah yang strategis dapat dijangkau dengan sarana transportasi umum maupun pribadi. Promotion (promosi) dilakukan melalui media cetak, elektronik dan media sosial. People (sumber daya manusia) meliputi pendidik dan tenaga kependidikan yang muda dan semangat. Physical evidence (bukti fisik) berupa gedung sekolah dan laporan hasil belajar siswa. Process (proses), penyelenggaraan pendidikan di kedua sekolah tersebut telah memenuhi standar nasional pendidikan.

Faktor pendukung dalam penerapan strategi Bauran Pemasaran di SMP Muhammadiyah Sinar Fajar Cawas adalah, animo masyarakat tinggi, pendidik (guru) yang masih muda, semangat dan mempunyai kreatifitas tinggi, program yang bervariasi, figur pendidik yang ditokohkan oleh calon siswa dan orang tua siswa. Faktor penghambat dalam penerapan strategi Bauran Pemasaran di SMP Muhammadiyah Sinar Fajar adalah, minimnya sarana dan prasarana sekolah, jaringan luar sekolah yang masih minim, serta terbatasnya sumber daya manusia dari segi jumlah dan kualitas. Faktor pendukung dalam penerapan strategi Bauran Pemasaran di SMP Islam Terpadu An Najah Jatinom adalah animo masyarakat yang tinggi, pendidik (guru) yang masih muda, semangat dan mempunyai kreatifitas tinggi, gedung sekolah yang bagus, nyaman, dan menarik, serta program yang bervariasi. Faktor penghambat dalam penerapan strategi Bauran Pemasaran di SMP Islam Terpadu Muhammadiyah An Najah Jatinom adalah, tenaga pendidik masih minim dari segi jumlah dan kualitas, pihak sekolah kurang konsisten dalam pelaksanaan program serta minimnya fasilitas penunjang pembelajaran.

Kata kunci: strategi bauran pemasaran; mutu sekolah; kepuasan pelanggan 


\section{PENDAHULUAN}

Permasalahan

di Indonesia saat ini sangatlah kompleks, Daoed Joefoef mencatat permasalahan internal pendidikan meliputi permasalahan - permasalahan yang berhubungan dengan strategi pembelajaran, peran guru dan kurikulum. ${ }^{1}, 2$. Salah satu permasalahan yang berhubungan dengan peran guru yakni, guru hanya berperan sebagai pengajar atau hanya sebatas memberikan materi kepada murid. Suyanto menjelaskan bahwa guru yang professional harus memiliki kualifikasi dan ciri-ciri tertentu. ${ }^{3}$ Kualifikasi dan ciri-ciri yang dimaksud adalah: (a) harus memiliki landasan pengetahuan yang kuat, (b) harus berdasarkan atas kompetensi individual, (c) memiliki sistem seleksi dan sertifikasi, (d) ada kerjasama dan kompetisi yang sehat antar sejawat, (e) adanya kesadaran profesional yang tinggi, (f) memiliki prinsip-prinsip etik, (g) memiliki sistem seleksi profesi, (h) adanya militansi individual, dan (i) memiliki organisasi profesi. Guru - guru saat ini banyak yang tidak sesuai dengan kriteria sebagai guru yang profesional.

Keberhasilan pendidikan, tidak terlepas dari peran guru sebagai pendidik yang handal dan berkualitas.Guru menjadi faktor utama dalam keberhasilan pendidikan, guru hendaknya mempunyai jiwa yang tulus dalam menjalankan tugasnya. Pendidik di sekolah yang disebut guru, harus memposisikan dirinya sebagai ibu dari anak didiknya. Jangan sampai, seorang guru yang dikenal hanya karena telah memberikan ilmu

1 Joesoef, Daoed, 2001. Pembaharuan Pendidikan dan Pikiran, dalam Sularto (ed). Masyarakat Warga dan Pergulatan Demokrasi: Antara Cita dan Fakta, Jakarta: Kompas.

2 Muhammad Fadhli, Manajemen Peningkatan Mutu Pendidikan, Tadbir Jurnal Studi Manajemen Pendidikan, Vol. 1, No. 02, 2017 hlm. 218

3 Suyanto, 2006. Dinamika Pendidikan Nasional (Dalam Percaturan Dunia Global). Jakarta: PSAP Muhammadiyah pengetahuan semata, melainkan juga

seorang guru yang memiliki kedekatan emosional yang penuh kasih sayang kepada anak didiknya sehingga dapat membentuk budi pekerti. ${ }^{4}$

Undang - Undang Sistem Pendidikan Nasional No.20 Tahun 2003 Pasal 42 ayat (1) menyebutkan bahwa pendidik harus memiliki kualifikasi minimum dan sertifikasi sesuai dengan jenjang kewenangan mengajar, sehat jasmani dan rohani, serta memiliki kemampuan untuk mewujudkan tujuan pendidikan nasional.

Selaras dengan undang - undang sistem pendidikan nasional sebagaimana yang telah disebutkan di atas, perlu adanya strategi yang tepat pada lembaga pendidikan guna mencetak pendidik yang handal sehingga tercapai tujuan pendidikan nasional. Keberhasilan pendidikan perlu diwujudkan dengan upaya peningkatan mutu pendidikan yang akan menjadi ruh kebehasilan pengelolaan sebuah lembaga pendidikan.

Mutu sekolah merupakan cita - cita dan harapan dari tiap pelanggan sekolah. Edward Sallis, menerangkan bahwa mutu merupakan filosofi tentang perbaikan secara terus menerus, yang dapat memberikan seperangkat alat praktis kepada setiap institusi pendidikan dalam memenuhi kebutuhan, keinginan, dan harapan para pelanggannya, saat ini dan untuk masa yang akan datang. ${ }^{5}$ Sallis juga mengungkapkan bahwa kualitas adalah bagian penting dari seluruh agenda dalam organisasi dan meningkatkan kualitas adalah tugas yang paling penting yang dihadapi institusi manapun. ${ }^{6}$ Tantangan

4 Muthoifin, Mohamad Ali, Nur Wachidah, Pemikiran Raden Ajeng Kartini Tentang Pendidikan Perempuan Dan Relevansinya Terhadap Pendidikan Islam, Jurnal Studi Islam, Vol. 18, No. 1, Juni 2017: 41

5 Edward Sallis, Total Quality Management in Education (Jogakarta;IRCisoD, 2012),hlm.73

6 Muhammad Fadhli, Manajemen Peningkatan Mutu Pendidikan, Tadbir: Jurnal Studi Manajemen Pendidikan, STAIN Curup-Bangkulu, Vol. 1, No 02, 2017 
kualitas pendidikan akan semakin jelas dan tidak bisa dihindari untuk menghadapi persaingan global. Dunia Pendidikan perlu melakukan perubahan seperti yang diungkapkan oleh Tilaar. ${ }^{7}$

Mutu harus ditingkatkan agar lembaga mampu memberikan bekal ilmu untuk kehidupan anak didik di masa yang akan datang. Ukuran sekolah yang bermutu dilihat dari kacamata pengguna atau pelanggan, yang mengacu pada penilaian sekolah seperti akreditasi, lulusan sekolah, pengajar yang profesional, hasil ujian nasional, prestasi peserta didik, dan karakter peserta didik.

Dalam pengembangan penjamin mutu diperlukan sikap profesional yaitu mereka yang mau secara penuh tanggung jawab pada tugasnya menuju keunggulan mutu (Elton, lewis.1995:132). Menurut Elton, Lewis (1995:135) secara umum pelaksanaan pemjamin mutu dilakukan dalam tiga tahapan : a. Kesepakatan tentang kebutuhan yang akan dipenuhi agar tercapai kepuasan b. Menetukan langkah - langkah yang akan dinilai kualitasnya c. Melakukan prosedur yang memastikan bahwa kualitas selalu terpelihara. ${ }^{8}$

Kepuasan pelanggan dapat dilihat dari cara sekolah memasarkan produk atau jasa itu sendiri kepada para pelanggan. Istilah pemasaran dalam dunia pendidikan tidak terlepas dari pemasaran pada umumnya, menurut Philip Kotler pemasaran adalah sebagai suatu proses sosial dan managerial yang membuat individu dan kelompok memperoleh apa yang mereka butuhkan dan inginkan melalui penciptaan dan pertukaran timbal balik produk dan nilai

7 Amrullah Aziz, Peningkatan Mutu Pendidikan, Jurnal Studi Islam, Vol. 10, No. 2, Desember 2015, hlm. 11

8 Eko Supriyanto, Model Penjaminan Mutu Pembelajaran Pada Perguruan Tinggi Swasta, Jurnal Varia Pendidikan, Vol. 24, No. 1, juni 2012, hlm. 3 dengan orang lain ${ }^{9},{ }^{10}$.

Manajemen pemasaran bagi lembaga pendidikan (terutama madrasah) diperlukan seiring adanya persaingan antar sekolah yang semakin atraktif. Pemasaran dibutuhkan bagi lembaga pendidikan dalam membangun citranya yang positif. Apabila sekolah atau lembaga memiliki citra yang baik di mata masyarakat, maka besar kemungkinan akan lebih mudah dalam mengatasi masalah. ${ }^{11} 12$

Bauran pemasaran merupakan salah satu strategi pemasaran untuk menyampaikan informasi secara luas, memperkenalkan suatu produk barang dan jasa, menarik konsumen untuk memberi bahkan menciptakan preferensi pribadi terhadap image suatu produk. Bauran pemasaran dianggap sebagai salah satu unsur strategi yang paling potensial didalam memasarkan produk. Strategi bauran pemasaran meliputi empat komponen yaitu : produk, harga, promosi dan tempat. Peranan penetapan harga dan promosi penjualan sangat penting terutama untuk membangun komitmen dan loyalitas pelanggan. ${ }^{13}$

Konsep bauran pemasaran merupakan salah satu strategi guna menyelesaikan berbagai persoalan pada lembaga pendidikan. Konsep bauran pemasaran ini harus dilakukan oleh lembaga pendidikan, jika tidak, maka lembaga pendidikan tersebut akan

$9 \quad$ Philip Kotler, Manajemen Pemasaran (Hendra Teguh dkk, Terjemahan Marketing Management. Jilid 1 ( Jakarta:PT. Perihallindo:1997), hlm. 8

10 Afidatun Khasanah, Pemasaran Jasa Pendidikan sebagai Strategi Peningkatan Mutu di SD Alam Baturraden, El Tarbawj Jurnal Pendidikan Islam, 2015, Vol 8, No. 2

11 Imam Faizin, Strategi Pemasaran Jasa Pendidikan dalam Meningkatkan Nilai Jual Madrasah. Jurnal Madaniyah, Vol. 7, No. 2 Edisi Agustus 2017

12 Muthoifin, Muthoifin. 2015. Pemikiran Pendidikan Multikultural Ki Hadjar Dewantara, dalam Jurnal Intizar, Vol. 21, No. 2: 299.

13 Christian A.D Selang, Bauran Pemasaran (Marketing Mix) Pengaruhnya Terhadap Loyalitas Konsumen Pada Fresh Mart bahu Mall Manado, Jurnal Emba Vol. 1 No 3, Juni 2013, hlm. 71-80 
mengalami kegagalan dalam menentukan arah perkembangan dan kemajuan lembaga.

Tujuan bauran pemasaran adalah untuk mereorientasi sistem manajemen, perilaku staf, fokus organisasi, proses pengadaan dan pelayanan sehingga organisasi dapat berproduksi dengan baik dan memberikan pelayanan yang lebih efektif yang dapat memenuhi kebutuhan dan keperluan pelanggan. Apabila tujuan tersebut dapat dicapai, maka strategi bauran pemasaran akan mendatangkan perbaikan pelayanan, pengurangan biaya dan kepuasan pelanggan.

Peyelenggaraan pendidikan di SMP Muhammadiyah Sinar Fajar Cawas dan SMP Islam TerpaduMuhammadiyah An Najah Jatinom Klaten, diorientasikan pada kepuasan pelanggan guna meningkatkan mutu pendidikan melalui strategi bauran pemasaran. Peneliti mengambil objek penelitian di SMP Muhammadiyah Sinar Fajar Cawas dan SMP Islam TerpaduMuhammadiyah An Najah Jatinom Klaten karena ada berbagai alasan yang menjadikan kedua tempat tersebut layak untuk diteliti. Pertama, kedua sekolah tersebut merupakan sekolah yang baru berdiri namun

keberadaannya mendapat respon yang bagus dari masyarakat, hal ini terlihat dari meningkatnya jumlah pendaftar siswa baru pada sekolah tersebut. Kedua, SMP Muhammadiyah Sinar Fajar Cawas dan SMP Islam TerpaduAn Najah Jatinom Klaten, mampu meraih berbagai kejuaraan dalam setiap event (perlombaan) baik ditingkat

kecamatan maupun Kabupaten.

Keberhasilan sebuah sekolah dalam berbagai aspek tentunya tidak lepas dari sistem manajemen yang baik sehingga menjadikan sekolah tersebut bermutu. SMP Muhammadiyah Sinar Fajar Cawas dan SMP Islam TerpaduMuhammadiyah An Najah Jatinom dapat dikatakan sebagai sekolah yang baik dalam dalam pengelolaan sekolah. Berdasarkan pencermatan inilah peneliti mengadakan penelitian dan menuliskan langkah langkah dalam penerapan strategi bauran pemasaran serta memberikan sebuah solusi terhadap hambatan yang dihadapi pada kedua sekolah tersebut berdasarkan kajian teori yang ada. ${ }^{14}$

\section{METODE PENELITIAN \\ Lokasi dan Subjek Penelitian}

Penelitian ini dilakukan di SMP Muhammadyah Sinar Fajar Cawas dan SMP Islam Terpadu Muhammadiyah An Najah Jatinom Klaten, dengan subjek primer penelitian adalah kepala sekolah, guru, peserta didik, masyarakat, dan pihak lain jika diperlukan.

\section{Pendekatan yang digunakan dan metode pengumpulan data penelitian}

Penelitian ini merupakan jenis penelitian lapangan dengan data yang diperoleh merupakan hasil dari penelitian lapangan yang dipadukan dengan teori- teori yang ada. Penelitian ini bersifat kualitatif, yaitu penelitian yang menempatkan subjek penelitian dalam posisi yang sama dengan peneliti, sehingga subjek penelitian merasakan seakan - akan sudah menjadi bagian dari kehidupannya, yaitu prosedur penelitian yang dilakukan dengan menggunakan data - data kualitatif berupa ungkapan kata - kata, baik secara langsung maupun berupa data tertulis dari orang atau pelaku yang diamati. ${ }^{15}$

Penelitian ini dinamakan jenis penelitian lapangan karena prosedur penelitian menggali sumber-sumber data dari lapangan yang dicermati dan ditemukan di lapangan yang

14 Muthoifin, Sistem Pendidikan Nasional dan Pendidikan Islam: Studi Kritis Pemikiran Ki Hadjar Dewantara Perspektif Islam, dalam Jurnal Wahana Akademika, Vol. 2, No. 1: 69-72.

15 Muru Yusuf, Metode Penelitian, Kuantitatif, Kualitatif, Dan Penelitian Gabungan (Jakarta Prenada Media Group, 2014) hlm. 24 
menghasilkan data deskriptif berupa kata-kata tertulis atau lisan dari orangorang dan pelaku yang diamati, diarahkan pada latar belakang individu secara utuh (holistik) tanpa mengisolasikan individu dan organisasi dalam variabel atau hipotesis, tetapi memandangnya sebagai satu kesatuan yang utuh. ${ }^{16}$

Penulis berupaya pada penelitian ini mengumpulkan data - data yang berkaitan dengan bauran pemasaran yang diterapkan dalam upaya meningkatkan mutu pendidikan di SMP Muhammadiyah Sinar Fajar Cawas dan di SMP Islam TerpaduMuhammadiyah An Najah Jatinom Klaten. Dalam hal ini peneliti memposisikan diri sebagai bagian dari pemeran sertanya dan mencatat secara seksama data yang diperoleh untuk kemudian dipadukan dengan teori-teori yang ada.

\section{Teknik Analisa atau interpretasi data}

Teknik Analisa data dalam penelitian ini bersifat kualitatif yang dilakukan seiring dengan proses pengumpulan data, dengan demikian pekerjaan mengumpulkan data yang dilakukan oleh peneliti diikuti dengan menuliskan, mengedit, mengklarifikasi, mereduksi, menyajikan, dan menarik kesimpulan atau verifikasi data.

\section{HASIL PENELITIAN DAN 4PEMBAHASAN}

1 Langkah - langkah yang telah dilakukan dalam penerapan strategi Bauran Pemasaran untuk meningkatkan mutu sekolah di SMP Muhammadiyah Sinar Fajar Cawas dan SMP Islam Terpadu Muhammadiyah An Najah Jatinom Klaten

Langkah - langkah yang dilakukan kedua sekolah tersebut adalah

16 Lexy J. Moleong, Metode Penelitian Kualitatif (Bandung, Remaja Rosda Karya,2001) hlm.3 dengan menerapkan langkah 7P, langkah tersebut meliputi, Product (produk) yang berupa variasi program pilihan. Price (harga), berupa biaya sekolah yang ditawarkan pada wali murid, pembayaran dapat dilakukan secara langsung atau melalui transfer. Place (tempat), lokasi kedua sekolah yang strategis dapat dijangkau dengan sarana transportasi umum maupun pribadi. Promotion (promosi) dilakukan melalui media cetak, elektronik dan media sosial. People (sumber daya manusia) meliputi pendidik dan tenaga kependidikan yang kompeten dan professional. Physical evidence (bukti fisik) berupa Gedung sekoah dan laporan hasil belajar siswa. Process (proses), penyelenggaraan pendidikan di kedua sekolah tersebut telah memenuhi standar nasional pendidikan.

2. Faktor pendukung dalam penerapan strategi Bauran Pemasaran di SMP Muhammadiyah Sinar Fajar Cawas dan SMP Islam Terpadu Muhammadiyah Jatinom

a. Faktor pendukung dalam penerapan strategi Bauran Pemasaran di SMP Muhammadiyah Sinar Fajar Cawas adalah : Animo masyarakat terhadap SMP Muhammadiyah Sinar Fajar cukup tinggi, hal ini dibuktikan dengan adanya daftar inden sebelum pendaftaran siswa baru dimulai. Pendidik (guru) di SMP Muhammadiyah Sinar Fajar masih muda - muda, dan mempunyai semangat serta kreatifitas yang tinggi, sehingga kegiatan belajar mengajar dapat berjalan dengan baik. Program yang ada diSMP Muhammadiyah Sinar Fajar bervariasi, sehingga menjadi daya tarik bagi calon 
siswa dan orang tua. Figur pendidik yang ditokohkan oleh calon siswa dan orang tua siswa, sehingga orang tua tidak ragu untuk menyekolahkan putra/ putrinya diSMP Muhammadiyah Sinar Fajar.

b. Faktor pendukung dalam penerapan strategi Bauran Pemasaran di SMP Islam Terpadu An Najah Jatinom adalah, animo masyarakat terhadap SMP Islam Terpadu Muhammadiyah An Najah Jatinom tinggi, hal ini dibuktikan dengan adanya daftar inden sebelum pendaftaran siswa baru dimulai. Pendidik (guru) di SMP Islam Terpadu Muhammadiyah An Najah Jatinom relatif masih muda - muda, dan mempunyai semangat serta kratifitas yang tinggi, sehingga kegiatan belajar mengajar dapat berjalan dengan baik. Gedung sekolah yang bagus, nyaman dan menarik, sehingga menjadi salah satu daya tarik calon pelanggan sekolah. Program yang ada di SMP Islam Terpadu Muhammadiyah An Najah Jatinom bervariasi, sehingga menjadi daya tarik bagi calon siswa dan orang tua.

3. Faktor penghambat dalam penerapan strategi Bauran Pemasaran di SMP Muhammadiyah Sinar Fajar Cawas dan SMP Islam Terpadu Muhammadiyah Jatinom
a. Faktor
dalam
penghambat
Bauran Pemasaran di SMP Muhammadiyah Sinar Fajar Cawas adalah : Minimnya sarana dan prasarana sekolah, jaringan luar sekolah yang masih minim, serta sumber daya manusia yang terbatas dari segi jumlah dan kualitas.

b. Faktor penghambat dalam penerapan strategi Bauran Pemasaran di SMP Islam Terpadu Muhammadiyah An Najah Jatinom adalah: Tenaga pendidik masih minim dari segijumlah dan kualitas, pihak sekolah kurang konsisten dalam pelaksanaan program serta minimnya fasilitas penunjang pembelajaran.

\section{KESIMPULAN}

Berdasarkan hasil penelitian dapat disimpulkan. SMP Muhammadiyah Sinar Fajar Cawas dan SMP Islam Terpadu Muhammadiyah An Najah Jatinom Klaten telah menerapkan strategi bauran pemasaran dalam upaya peningkatan mutu sekolah yakni dengan menerapkan strategi 7P yang meliputi : product (produk), price (harga), place (tempat), promotion (promosi) people (sumber daya manusia), physical evidence (bukti fisik). process (proses), Faktor pendukung dalam penerapan strategi Bauran Pemasaran di SMP Muhammadiyah Sinar Fajar Cawas adalah: Animo masyarakat yang tinggi, pendidik mempunyai semangat serta kratifitas yang tinggi, program yang ada bervariasi, figur pendidik yang ditokohkan oleh calon siswa dan orang tua siswa. Faktor pendukung dalam penerapan strategi Bauran Pemasaran di SMP Islam Terpadu Muhammadiyah An Najah Jatinom adalah : Animo masyarakat yang tinggi, pendidik mempunyai semangat serta kratifitas yang tinggi, program yang ada bervariasi, gedung sekolah yang bagus, nyaman dan menarik, sehingga menjadi salah satu daya tarik calon pelanggan sekolah. Faktor penghambat dalam penerapan strategi Bauran Pemasaran di SMP Muhammadiyah Sinar Fajar Cawas adalah : minimnya sarana dan prasarana sekolah, jaringan luar sekolah yang masih minim, serta sumber daya manusia yang terbatas dari segi jumlah dan kualitas. Faktor 
penghambat dalam penerapan strategi minim dari segi jumlah dan kualitas, Bauran Pemasaran di SMP Islam Terpadu pihak sekolah kurang konsisten dalam Muhammadiyah An Najah Jatinom pelaksanaan program serta minimnya adalah : tenaga pendidik yang masih fasilitas penunjang pembelajaran.

\section{DAFTAR PUSTAKA}

Joesoef, Daoed. 2001. Pembaharuan Pendidikan dan Pikiran, dalam Sularto (ed). Masyarakat Warga dan Pergulatan Demokrasi: Antara Cita dan Fakta, Jakarta: Kompas.

Kotler, Philip. 1997. Manajemen Pemasaran, Terj. Hendra Teguh dkk. Jakarta: PT. Perihallindo.

Suyanto, 2006. Dinamika Pendidikan Nasional (Dalam Percaturan Dunia Global). Jakarta: PSAP Muhammadiyah

Sallis,Edward. 2012. Total Quality Management in Education. Jogakarta :IRCisoD.

A. D Selang, Christian. 2013. Bauran Pemasaran (Marketing Mix) Pengaruhnya Terhadap Loyalitas Konsumen Pada Fresh Mart bahu Mall Manado, Jurnal Emba Vol. 1 No 3, : 71-80

Aziz, Amrullah. Peningkatan Mutu Pendidikan. Jurnal Studi Islam, Vol.10, No.2 : 2015

Fadhli,Muhammad. 2017. Manajemen Peningkatan Mutu Pendidikan, Tadbir Jurnal Studi Manajemen Pendidikan, Vol.1, No. 02 : 218

Fadhli, Muhammad.2017. Manajemen Peningkatan Mutu Pendidikan. Tadbir Jurnal Studi Manajemen Pendidikan, Vol. 1, No. 02 : 2017

Faizin, Imam. 2017. Strategi Pemasaran Jasa Pendidikan dalam Meningkatkan Nilai Jual Madrasah. Jurnal Madaniyah, Vol. 7, No. 2 : 280 - 281

J. Moleong, Lexy.2001. Metode Penelitian Kualitatif. Bandung : Remaja Rosda Karya.

Khasanah,Afidatun 2015. Pemasaran Jasa Pendidikan sebagai Strategi Peningkatan Mutu di SD Alam Baturraden, El Tarbawj Jurnal Pendidikan Islam, Vol. 8, No. 2

Muthoifin, Mohamad Ali, Nur Wachidah, 2017. Pemikiran Raden Ajeng Kartini Tentang Pendidikan Perempuan Dan Relevansinya Terhadap Pendidikan Islam, Jurnal Studi Islam, Vol. 18, No. $1: 41$

Muthoifin. 2015. Pemikiran Pendidikan Multikultural Ki Hadjar Dewantara, dalam Jurnal Intizar, Vol. 21, No. 2: 299.

Muthoifin. 2015. Sistem Pendidikan Nasional dan Pendidikan Islam: Studi Kritis Pemikiran Ki Hadjar Dewantara Perspektif Islam, dalam Jurnal Wahana Akademika, Vol. 2, No. 1: 69-72.

Supriyanto, Eko.201. Model Menjaminan Mutu Pembelajaran Pada Perguruan Tinggi Swasta, Jurnal Varia Pendidikan, Vol. 24, No. 1: 3

Yusuf, Muru. 2014. Metode Penelitian, Kuantitatif, Kualitatif, Dan Penelitian Gabungan. Jakarta. Prenada Media Group. 